\title{
In vitro biofilm formation and antibiotic susceptibility of Pseudomonas aeruginosa isolated from airways of patients with cystic fibrosis
}

\author{
Jolanta Długaszewska, Marta Antczak, Izabella Kaczmarek, Renata Jankowiak, \\ Małgorzata Buszkiewicz, Magdalena Herkowiak, Klaudia Michalak, Helena Kukuła, \\ Magdalena Ratajczak
}

Department of Genetics and Pharmaceutical Microbiology, Poznan University of Medical Sciences, Poland

\begin{abstract}
Introduction. Pseudomonas aeruginosa is the predominant cause of airway infections in patients with cystic fibrosis (CF) as a result of its ability to form biofilm. Resistance to antimicrobial agents is the most important feature of biofilm infection. The aim of this study was to evaluate biofilm formation and to compare antibiotic susceptibility of $P$. aeruginosa living in two modes of growth: planktonic and biofilm, isolated from respiratory tract of CF patients.

Material and Methods. Biofilm formation and biofilm susceptibility to antibiotics were determined using modified microtitere plate method. For susceptibility testing of planktonic culture to antibiotics serial microdilution broth method were used.

Results. More than $95 \%$ of isolates were capable to form biofilm. Isolates grown as biofilms were more resistant to tested antibiotics compared to those grown planktonically. Ciprofloxacin showed the highest activity against $P$. aeruginosa biofilm. In contrast, no bacteriostatic activity was obtain for the highest concentration of piperacillin tested against most of $P$. aeruginosa strains growing in a biofilm (BIC $>4096 \mathrm{mg} / \mathrm{L}$ ).

Conclusions. Our study indicates the need to develop a standardized susceptibility testing method for biofilm mode of growth of pathogens. It appears that it is appropriate to introduce a biofilm susceptibility testing to routinely performed tests, as the effect of antibiotics on biofilm eradication may be variable and unpredictable.
\end{abstract}

Keywords: biofilm resistance, chronic infections, susceptibility testing.

\section{Introduction}

Pseudomonas aeruginosa is a ubiquitous Gram-negative bacterium that grows in soil, water, as well as on plant and animal tissues. Because of ability of this bacterium to product multiple virulence factors facilitating invasion and colonization, $P$. aeruginosa is a major opportunistic human pathogen responsible for bacteremia in burn patients, urinary-tract infections in catheterized patients, and pneumonia in mechanically ventilated patients [1-3]. $P$. aeruginosa is also the predominant cause of lung infections in cystic fibrosis patients [4]. The pathogenesis of $P$. aeruginosa lung infections is multifactorial and depends on numerous virulence factors, including secretion of extracellular enzymes (e.g. elastase, phospholipase C, alkaline protease, exotoxin A, pyoverdine, neuraminidase) and the presence of cell associated factors, such as flagella, pili and lipopolysaccharide (LPS) $[5,6]$. Another important factor contributing to the pathogenesis of $P$. aeruginosa severe infections is its tendency to form organized communities, known as a biofilm, on biotic and abiotic surfaces [7]. Natural resistance of $P$. aeruginosa to several group of antibiotics, and the resistance to disinfectants together with the ability to biofilm for- 
mation make this bacterium responsible for high rates of morbidity and mortality [8, 9].

The discovery of bacteria existing in a biofilm form has led many researches to revisit the pathogenesis of chronic infections. Biofilm is three-dimensional structured, specialized community of adherent microorganisms enclosed in a self-produced extracellular polymeric substance (EPS). Resistance of biofilm towards component of host immune system as well as antimicrobial agents appears to be risk factor for persistent infections and makes them difficult to eradicate $[8,10]$.

Bacteria living in biofilm undergo a phenotypic shift in behavior, and large groups of bacterial genes are differentially regulated. In this way, biofilm community obtains numerous advantages, such as passive resistance, metabolic cooperation, byproduct influence, quorum sensing systems, an enlarged gene pool with more efficient DNA sharing, and many other features which help bacteria to adapt to environmental condition and protect them from effects of external factors [11-13].

Cystic fibrosis (CF) is a genetic disorder due to recessive mutations in the $\mathrm{CF}$ transmembrane regulator gene which regulates chloride transport across epithelia cells. These mutations lead to dysfunction of the CF transmembrane regulator protein which constitutes a part of a chloride channel. This can result in a built-up of thick, sticky mucus, among others, in the respiratory tract, pancreas, and reproductive organs leading to multiple organ disorders. The span life and quality of life are most often dependent on changes in respiratory tract. As a result of hyperinflammation and a reduced ability to remove bacteria by mucociliary action, bacteria colonize the lungs [14]. Chronic airway infections in CF patients differ significantly from acute pulmonary infection in non-CF patients, bloodstream or urinary tract infections. $P$. aeruginosa grows in the CF lung very slowly as chronic biofilm infections and despite the use of a range of antipseudomonal antibiotics, eradication of the infection is quite rare [15-17].

This study was performed to compare antibiotic susceptibility of $P$. aeruginosa isolated from respiratory tract CF patients living in two modes of growth: planktonic and biofilm.

\section{Material and Methods}

Investigated bacterial strains

Pseudomonas aeruginosa strains were obtained from Microbiological Laboratory of Transfiguration of the
Lord Clinical Hospital. The strains originally isolated from respiratory tract of CF patient were frozen and stored in Microbank cryogenic vials (ProLabDiagnostics, Canada) at $-70 \pm 10^{\circ} \mathrm{C}$. Before each experiment subcultures were prepared on Tryptic soy agar (bioMérieux, Poland).

Staphylococcus epidermidis ATCC 35984, with a proven biofilm-forming ability and Staphylococcus epidermidis ATCC 35983 - a non-biofilm producer were used as positive and negative controls for biofilm production, respectively. Pseudomonas aeruginosa ATCC 27853 was applied as the quality control strain to verify the test procedures for determination of MIC.

Antibiotics applied in MBC and BIC determination Piperacillin (PIP), ceftazidime (CAZ), ciprofloxacin (CIP) and amikacin (AN) were obtained from Sigma-Aldrich (Poland). Stock solution from dry powders were prepared at a concentration of $4096 \mathrm{mg} / \mathrm{L}$ for piperacillin and $1024 \mathrm{mg} / \mathrm{L}$ for ceftazidime, amikacin and ciprofloxacin. The stock solutions were stored at $-70 \pm 10^{\circ} \mathrm{C}$ before experiments.

\section{Biofilm formation assay}

Biofilm formation was determined by the microtiter plate assay, as previously reported [18]. Briefly, $200 \mu \mathrm{L}$ of an overnight cultures grown on tryptic soy agar (bioMérieux, France) suspended in a tryptic soy broth (bioMérieux, France) and adjusted to a turbidity of $0.5 \mathrm{Mac}$ Farland in tryptic soy broth (TSB) were inoculated into 96-well flat-bottom microtiter plates (Medlab-Products Ltd., Poland) and incubated. Following incubation at $37^{\circ} \mathrm{C}$ for 20 hours the cultures were removed and the wells were washed three times with $200 \mu \mathrm{L}$ of phosphate buffered saline (PBS, $\mathrm{pH}=7.4$; Sigma-Aldrich, Poland) and dried at room temperature. Biofilms were stained with $0.1 \%$ crystal violet (Merck, Poland) for 15 minutes, washed with water and air dried overnight. The crystal violet from stained biofilm was resuspended in $250 \mu \mathrm{L}$ of $95 \%$ ethanol. The optical density (OD) of adherent biofilm was measured using an Infinite M200 (Tecan) plate reader at a wavelength of $590 \mathrm{~nm}$. Wells containing uninoculated TSB media served as a negative control. Tests were repeated three times. The interpretation of biofilm formation was done according to the Stepanovic criteria presented in Table 1 [19].

\section{Susceptibility testing of planktonic cells}

The stock solution of each antibiotic was two-fold serially diluted in a Mueller Hinton II broth (MHB II; bioMérieux, Poland) to concentrations ranging from 256 
Table 1. Classification of biofilm formation

\begin{tabular}{lc}
\hline \multicolumn{1}{c}{$O D$ values } & Biofilm formation \\
\hline$\leq O D C$ & None \\
\hline $2 \times O D C \geq O D>O D C$ & Weak \\
\hline $4 \times O D C \geq O D>2 \times O D C$ & Moderate \\
\hline $4 \times$ ODC & Strong \\
\hline$O D C=$ mean OD of control probes $+3 S D, O D-$ optical density, SD - standard deviation
\end{tabular}

Table 2. Detection of biofilm formation by the microtiter plate method

\begin{tabular}{lccc}
\hline Biofilm formation & No of isolates [\%] & Isolate & Absorbance at $590 \mathrm{~nm}$ \\
\hline None & $1[4.5]$ & 51 & 0.200 \\
\hline Weak & $1[4.5]$ & 14 & 0.419 \\
\hline Moderate & $2[9.0]$ & 23,26 & $0.517-0.694$ \\
\hline Strong & $18[82.0]$ & $4,5,9,13,16,20,24,28,29,30,31,32,33,37,38,39,40,52$ & $1.069->3.00$ \\
\hline
\end{tabular}

to $0.5 \mathrm{mg} / \mathrm{L}$. Aliquot of $100 \mu \mathrm{L}$ of each dilution were distributed into the wells of a sterile 96-well microtiter plate. An overnight bacterial culture was suspended in MHB II, adjusted to a $0.5 \mathrm{McFarland}$ standard, corresponding to a concentration of $10^{8} \mathrm{CFU} / \mathrm{mL}$ and diluted 1:100 in MHB II. Bacterial suspensions were added to all wells except the wells, which were used as sterility controls. Growth wells (with bacteria and without antibiotics) were also included. The final concentration of bacteria was c.a. $5 \times 10^{5} \mathrm{CFU} / \mathrm{mL}$ and final concentrations of antibiotics ranged from $0.25 \mathrm{mg} / \mathrm{L}$ to $128 \mathrm{mg} /$ $\mathrm{mL}$. The plates were prepared in triplicate and then incubated at $37^{\circ} \mathrm{C}$ for $20 \mathrm{~h}$. The MIC was determined as the lowest concentration of antibiotic that inhibited the visible growth of the tested microorganism.

\section{Biofilm susceptibility assay}

Antimicrobial susceptibility of $P$. aeruginosa biofilm assay was performed according to Moscowitz [20] with modifications. Briefly, bacterial biofilm was formed by immersing the wells of flat-bottom microtiter plates as described above. Negative control wells were filled with sterile medium. The 24-hour biofilms were washed three times with PBS solutions and air-dried. Serial two-fold dilutions of antibiotics, ranging from $4 \mathrm{mg} / \mathrm{L}$ to $4096 \mathrm{mg} / \mathrm{L}$, were prepared in MHB II. Next, $100 \mu \mathrm{L}$ of each concentration was added to each corresponding well and plates were incubated $18 \mathrm{~h}$ at $37^{\circ} \mathrm{C}$. Antibiotics were aspirated gently after incubation and plates were washed three times with sterile PBS solution. To each well $100 \mu \mathrm{l}$ of MHB II was added and the plates were sonicated using sonicating water bath for 5 minutes to disrupt the biofilm. The optical density at $650 \mathrm{~nm}$ $\left(\mathrm{OD}_{0 \mathrm{~h}}\right)$ was measured on a microtiter plate reader (Infi- nite $\mathrm{M} 200$,Tecan) before and after incubation at $37^{\circ} \mathrm{C}$ for $6 \mathrm{~h}$. Adequate biofilm growth for the positive control wells was defined as a mean $O_{650}$ difference $\left(O_{650}\right.$ at $6 \mathrm{~h}$ minus the $\mathrm{OD}_{650}$ at $0 \mathrm{~h}$ ). The biofilm inhibitory concentrations (BICs) were defined as the lowest concentrations of drug that resulted in an $\mathrm{OD}_{650}$ difference at or below $10 \%$ of the mean of two positive control well readings. The $10 \%$ cut-off represents a $1-\log 10$ difference in growth after $6 \mathrm{~h}$ of incubation.

\section{Statistical analyses}

The results of antimicrobial activity were analyzed using Kruskal-Wallis test. $P$ value $<0,05$ was considered as significant. The STATISTICA software was used in the statistical analyzes.

\section{Results}

\section{Biofilm formation}

The established cut-off values of ODc for assessment of biofilm formation for all strains were 0.157. Final OD value of tested strains was calculated as an average $O D$ value of the strain reduced by $O D c$ value. The interpretation of biofilm formation was performed according to the following criteria: $O D \leq 0.157$ - none producer; $0.157>0 \mathrm{OD} \leq 0.313$ - weak producer, 0.313 $>\mathrm{OD} \leq 0.626$ - moderate producer and $\mathrm{OD}>0.626$ strong producer (Table 2). Of the 22 isolates, 21 formed biofilm, of which only one was weak producer, two strains were moderate and 18 strong producers with an average $\mathrm{OD}_{650}$ value of $0.418 \pm 0.078,0.516 \pm 0.027-$ $0.694 \pm 0.042$ and $1.069 \pm 0.540->3.000$ respectively. For the six strains OD value were above upper limit of measurement range of plate reader $(O D>3.000)$. 
Effect of PIP on biofilm and planktonic P. aeruginosa mode of growth

Significant difference was observed between the inhibitory effect of piperacillin on biofilm and planktonic culture of $P$. aeruginosa CF isolates (Figure 1). The MIC value ranged from $4 \mathrm{mg} / \mathrm{L}$ to $64 \mathrm{mg} / \mathrm{L}$ and according to European Committee on Antimicrobial Susceptibility Testing (EUCAST) susceptibility breakpoints (>16 mg/L) only three strains were resistant to PIP. In contrast, no bacteriostatic activity was obtain for PIP at the highest concentration tested against most of $P$. aeruginosa strains growing in biofilm $(\mathrm{BIC}>4096 \mathrm{mg} / \mathrm{L})$ and the $\mathrm{BIC}$ was from 64 to > 1024 fold higher than MIC.

\section{Effect of CAZ on biofilm and planktonic $P$. aeruginosa} mode of growth

Figure 2 presents the MIC and BIC of ceftazidime for $P$. aeruginosa isolates. The obtained BIC values, ranged from $64 \mathrm{mg} / \mathrm{L}$ to $512 \mathrm{mg} / \mathrm{L}$, and were 8 to 64 fold higher than MICs. There were no correlation in differences between planktonic and biofilm inhibition concentra- tions and susceptibility assessed according EUCAST guidelines.

Effect of AN on biofilm and planktonic P. aeruginosa mode of growth

Determination of MIC for planktonic culture of $P$. aeruginosa showed that the majority of tested strains were susceptible to amikacin (MIC ranged $4-8 \mathrm{mg} / \mathrm{L}$ ), six were intermediate susceptible (MIC $16 \mathrm{mg} / \mathrm{L}$ ) and only one was resistant (MIC 64 mg/L) (Figure 3). Antibiofilm activity of amikacin for all tested isolates decreased and $\mathrm{BIC}$ value increased from 2 to 8 -fold in relation to MIC.

\section{Effect of CIP on biofilm and planktonic P. aeruginosa} mode of growth

Planktonic cultures of $P$. aeruginosa isolates were inhibited at ciprofloxacin concentration of $4 \mathrm{mg} / \mathrm{L}$ to $16 \mathrm{mg} / \mathrm{L}$ (Figure 4). Despite the fact that $P$. aeruginosa isolates cultured in floating form were resistant to CIP (according to EUCAST breakpoints), the concentration inhibiting the growth of $P$. aeruginosa biofilm (BICs) were equal or two to four-fold higher than MICs.

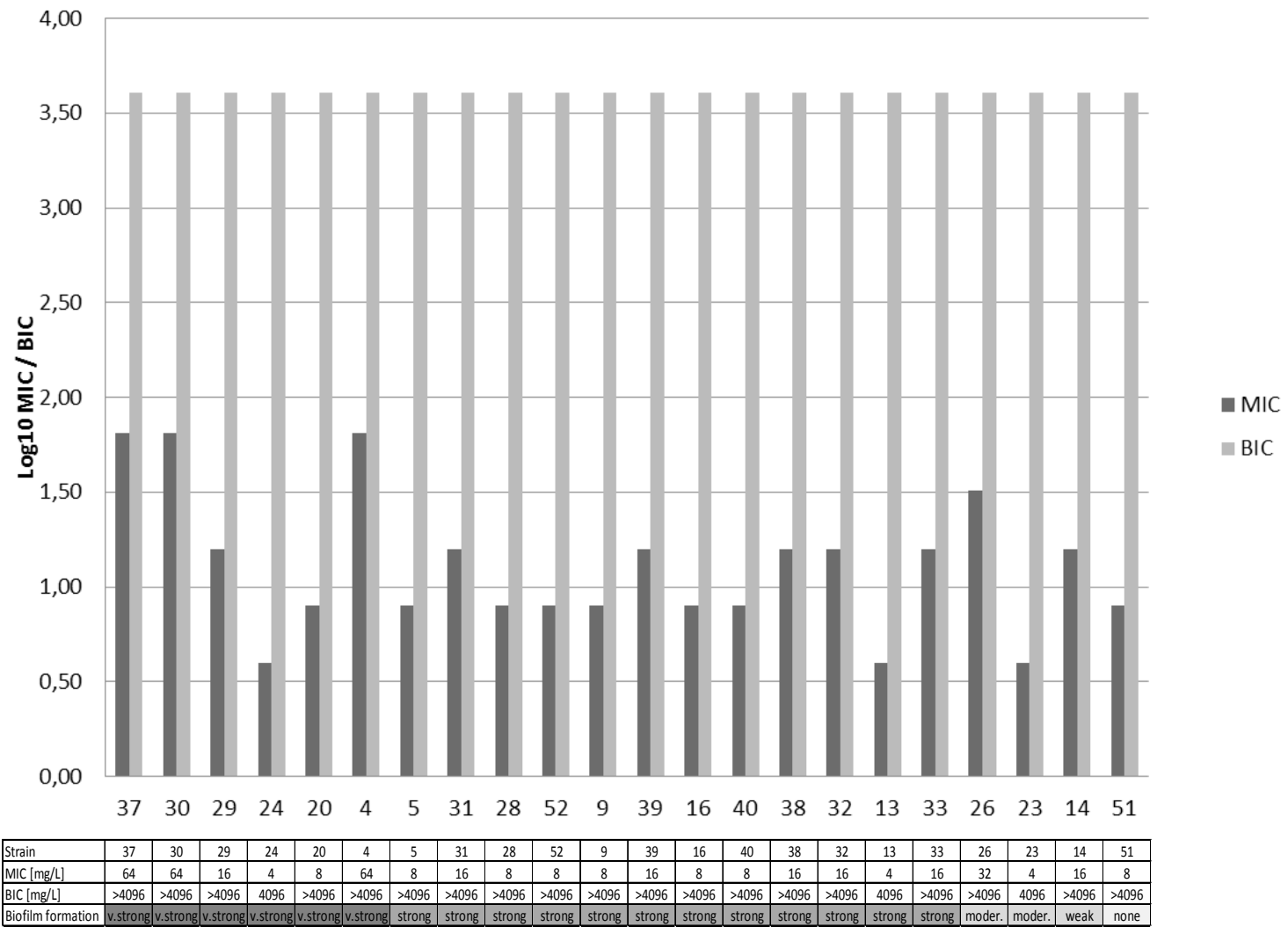

Figure 1. Comparison of planktonic (minimal inhibitory concentration, MIC,) and biofilm (biofilm inhibitory concentration, BIC) susceptibility of $P$ seudomonas aeruginosa isolates to piperacillin obtained from the airway of patients with cystic fibrosis. The MIC and BIC values are given in terms of $\log _{10} \mathrm{mg} / \mathrm{L}$. Susceptibility to piperacillin was not correlated to the intensity of biofilm formation by the strains tested 


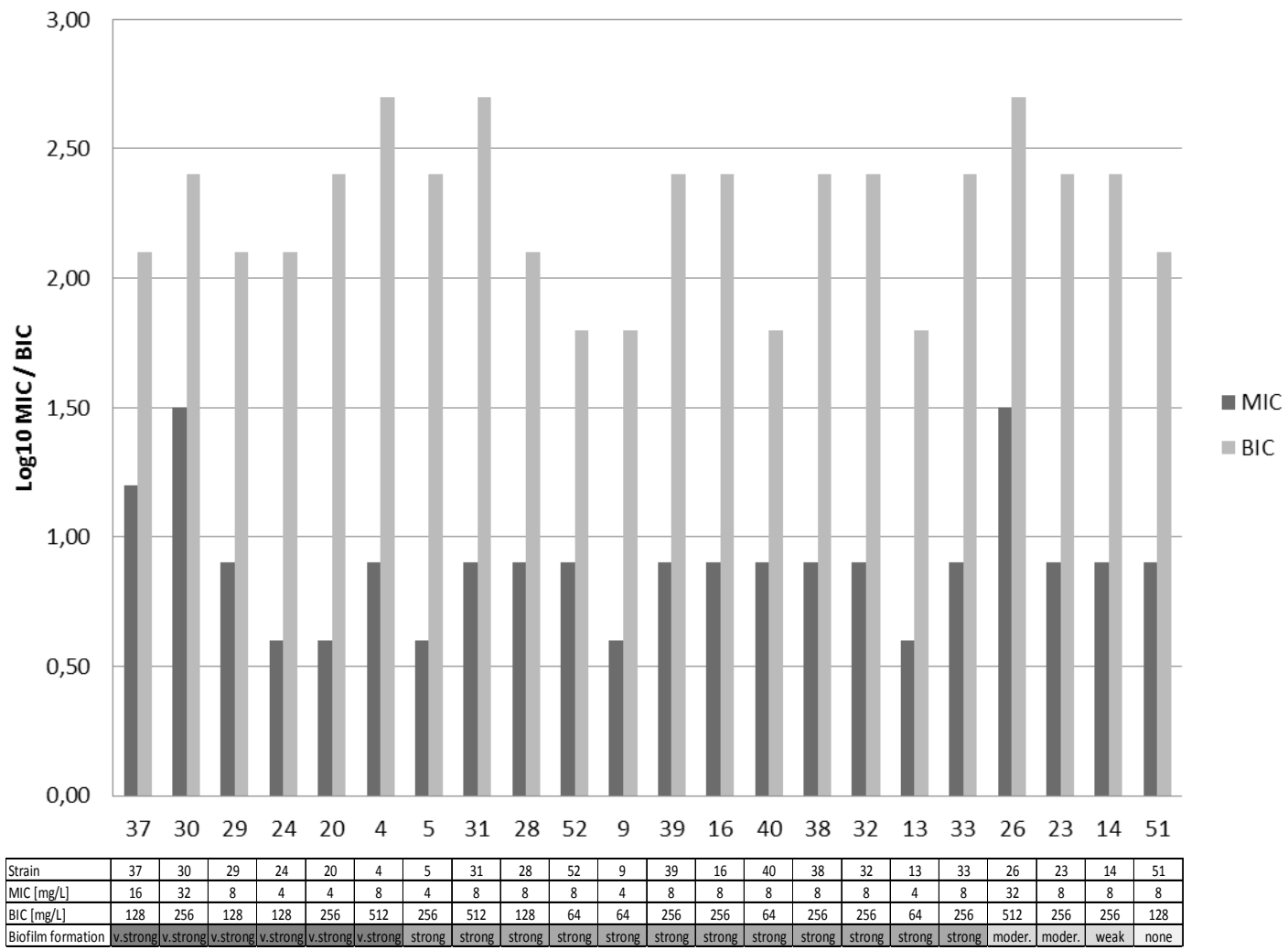

Figure 2. Comparison of planktonic (minimal inhibitory concentration, MIC,) and biofilm (biofilm inhibitory concentration, BIC) susceptibility of Pseudomonas aeruginosa isolates to ceftazidime obtained from the airway of patients with cystic fibrosis. The MIC and BIC values are given in terms of $\log _{10} \mathrm{mg} / \mathrm{L}$. Susceptibility to ceftazidime was not correlated to the intensity of biofilm formation by the strains tested

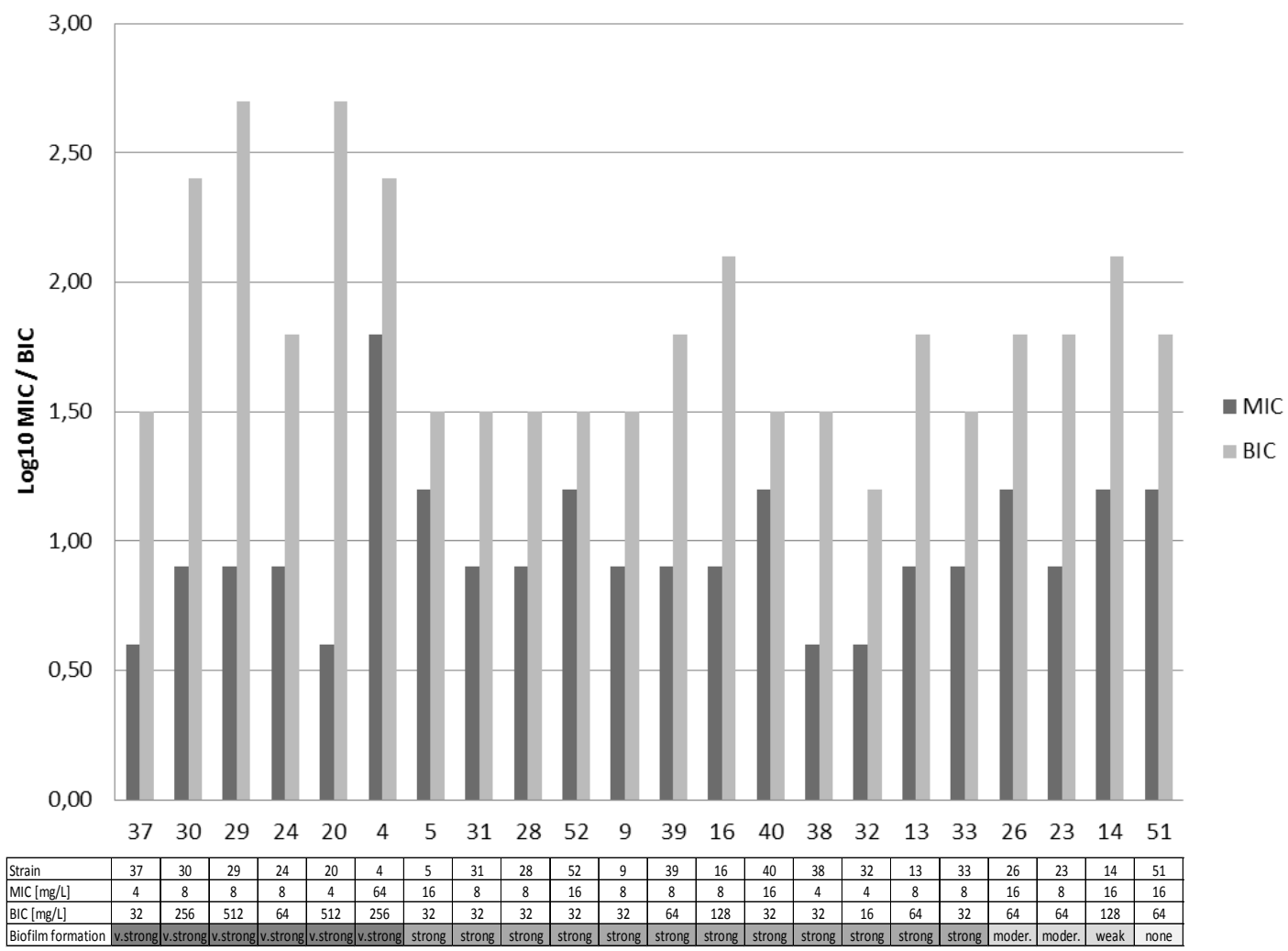

Figure 3. Comparison of planktonic (minimal inhibitory concentration, MIC,) and biofilm (biofilm inhibitory concentration, BIC) susceptibility of Pseudomonas aeruginosa isolates to amikacin obtained from the airway of patients with cystic fibrosis. The MIC and BIC values are given in terms of $\log _{10} \mathrm{mg} / \mathrm{L}$. Susceptibility to amikacin was not correlated to the intensity of biofilm formation by the strains tested 


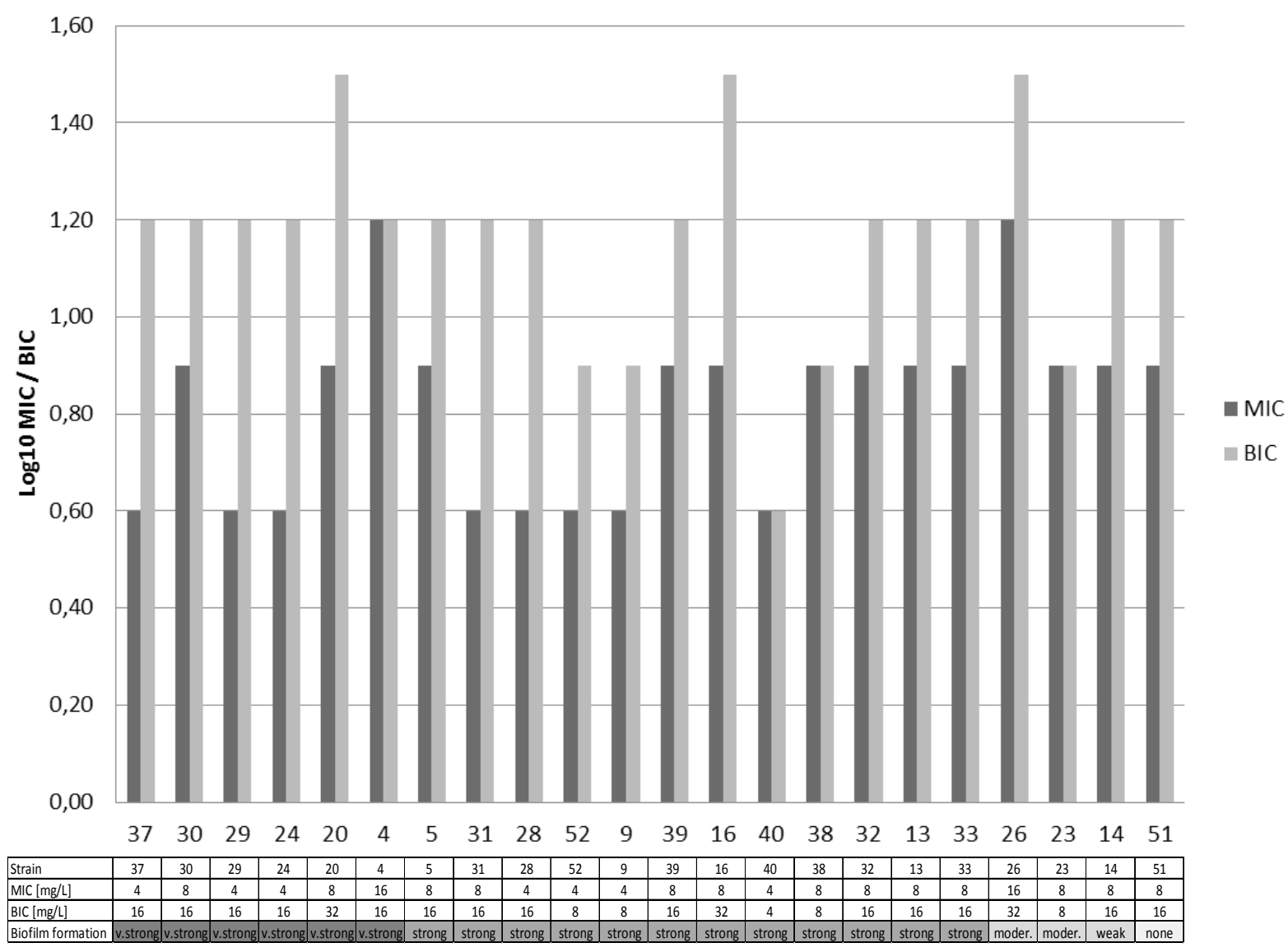

Figure 4. Comparison of planktonic (minimal inhibitory concentration, MIC,) and biofilm (biofilm inhibitory concentration, BIC) susceptibility of Pseudomonas aeruginosa isolates to ciprofloxacin obtained from the airway of patients with cystic fibrosis. The MIC and BIC values are given in terms of $\log _{10} \mathrm{mg} / \mathrm{L}$. Susceptibility to ciprofloxacin was not correlated to the intensity of biofilm formation by the strains tested

\section{Correlation between biofilm formation and biofilm} resistance

No significant correlation was observed between biofilm formation and BICs value for all tested antibiotics (Figures 1-4). No biofilm producer (strain No 51), weak (strain No 14) and moderate biofilm producers (strains No 23,26$)$ were equal to or more resistant to antibiotics than strong producers (e.g. strains No 13, 40, 9, 52, $28,37)$.

\section{Discussion}

As bacteria were usually considered as free-living, unicellular organisms, we are aware now that they exist predominantly as adherent multicellular biofilms in diverse environmental niches. Most of the bacteria have the ability to form a biofilm on different surfaces and in various organs, such as implants, urinary catheters, teeth or lung tissue [21-23]. According to the data obtained from Centers for Disease Control and Prevention (CDC), biofilms are the background of at least $65 \%$ of all human bacterial infectious $[24,25]$. Understanding bacterial physiology and the mechanisms of bac- terial resistance to lethal concentrations of antibiotics it is crucial to elaborate on the effective eradication of resistant strains [26-29].

$P$. aeruginosa is a prime example of bacteria known to grown in a biofilm form [30-32]. Recent evidence indicating a biofilm mode of growth in the respiratory tract and the presence of biofilm quorum-sensing signals in the sputum of $C F$ patients support the contestation that $P$. aeruginosa biofilms are present in an airway of cystic fibrosis patients [33,34]. Many reports provided strong evidence for potential role of $P$. aeruginosa biofilm in pathogenesis of lung infections in CF patients. Bjarnsholt et al [35] detected both biofilm forming microcolonies and non adhered planktonic bacteria in samples of sputum from 77 chronic $P$. aeruginosa infected $\mathrm{CF}$ patients in that study and no other bacteria were isolated. In our study in vitro biofilm-forming capacity of $P$. aeruginosa isolated from airway CF patients were detected in more than $95 \%$ strains but with diverse intensity. The variability in biofilm formation amongst $P$. aeruginosa isolates was supported by others $[7,9,13$, $26,36]$. The reason for the variety in biofilm formation seems to be multifactorial $[26,35,37]$. 
Comparison of MICs and BICs demonstrated differences in activity of tested antibiotics. In general, sessile bacteria were inhibited by much higher concentrations of antibiotics than floating cells.

The huge increase in biofilm resistance to antibiotics occurred with piperacillin. Most isolates grown in planktonic culture were susceptible to piperacillin, however, we observed a loss of activity of PIP (BICs $\geq$ $4096 \mathrm{mg} / \mathrm{L}$ ) when these isolates were grown as biofilms. For ceftazidime the BIC values for all strains were much more lower than for piperacillin, but still high (8 to $64 \times \mathrm{MIC}$ ). The reason why these $\beta$-lactam antibiotics are not as active against biofilm as it is on planktonic cell is that $\beta$-lactam antibiotic required rapid cells growth to kill the bacteria.

Amikacin, the aminoglycoside antibiotic was slightly more effective against $P$. aeruginosa biofilm than ceftazidime. Fluoroquinolone - ciprofloxacin showed the lack of therapeutic useful activity (MIC higher than EUCAST clinical breakpoint) against planktonic cell, but against the biofilm-forming cells, compared with the other antibiotics, the inhibiting concentrations were lower.This is supported by some investigators [38, 39,40 ] which indicated that $\beta$-lactam were less active antibiotics against sessile $P$. aeruginosa, in contrast to fluoroquinolones which were most active.

These results are in accordance with commonly accepted statement that biofilms are more resistant to antibiotics than planktonic cells $[38,41]$. Currently we are aware that the resistance of bacteria living in the biofilm is not associated directly with mutations characteristic to specific strain. Several factors have been suggested to explain the biofilms resistance to antibiotics for example presence of exopolysaccharide substance that can slow the diffusion of antimicrobials. One hypothesis is that reduction in antibiotics penetration through the biofilm is owing to an alginate, synthesized by $P$. aeruginosa an exopolysaccharide, which acts as a barrier for biocides. The permeability studies of the alginate indicated that this factor was not the most important barrier for azithromycin, erythromycin and ceftazidime as their penetration rates were respectively $100 \%, 100 \%$ and $95 \%$, and the bactericidal activity was low (bactericidal concentration $\geq$ $2560 \mathrm{mg} / \mathrm{L})$ [42].

Biofilm resistance to antibiotics must thus be considered as a combination of the transfer limitation and other factors such as slow growth and decreased metabolic activity, neutralization of the antibiotics by biofilm matrix components (e.g. ability of negatively charged biofilm components to bind cationic com- pounds), and modifications in gene expression and cell physiology [7, 39, 43, 44].

Results of our study indicate that the effects of antibiotics on biofilm eradication may be variable and unpredictable. This makes it difficult for clinicians to choose the most active antibiotic. Antibiotics should be selected on individual bases, and the assessment of their effectiveness on both bacterial forms, planktonic and in a biofilm should be performed. Then an antibiotic therapy will have a chance of success. Our study suggest the need to develop and to introduce a standardized susceptibility testing method for biofilm mode of growth of pathogens into routinely performed tests as a part of clinical care, especially for patients suffered from CF.

\section{Acknowledgements}

The authors thank Anna Mol, MSc., the supervisor of Microbiological Laboratory of Transfiguration of the Lord Clinical Hospital in Poznan, for the bacterial strains which were necessary to perform the experiments.

\section{Conflict of interest statement}

The authors declare no conflict of interest.

\section{Funding sources}

There are no sources of funding to declare.

\section{References}

1. Gellatly SH. Hancock REW, Pseudomonas aeruginosa: new insights into pathogenesis and host defenses. Pathogens and Disease. 2013 Apr;67:159-173.

2. Hauser AR, Rello J. Molecular Pathogenesis of Acute Pseudomonas aeruginosa Infections. In: Severe Infections Caused by Pseudomonas aeruginosa. Springer Science+Business Media, New York 2003; p. 204-212.

3. Campa M, Bendinelli M, Friedman H. Phenazine Pigments in Pseudomonas aeruginosa Infection. In: Pseudomonas aeruginosa as an Opportunistic Pathogen. Springer Science+Business Media, New York 1993; p. 43-54.

4. Winstanley C, O'Brien S, Brockhurst MA. Pseudomonas aeruginosa Evolutionary Adaptation and Diversification in Cystic Fibrosis Chronic Lung Infections. Trends Microbiol. 2016 May;24(5):327-37.

5. Rusiecka-Ziółkowska J, Fleischer M, Staroszczyk J. Właściwości immunologiczne Gram-ujemnych pałeczek Pseudomonas aeruginosa. Postępy Hig Med Dosw. 2007;(61):95-98.

6. Kazmierczak BI, Schniederberend M, Jain R. Cross-regulation of Pseudomonas motility systems: the intimate relationship between flagella, pili and virulence. Curr Opin Microbiol. 2015 Dec;28:78-82.

7. Harmsen M, Yang L, Pamp SJ, Tolker-Nielse T. An update on Pseudomonas aeruginosa biofilm formation, tolerance, and dispersal, FEMS Immunol Med Microbiol. 2010 Aug;59(3):253-268.

8. Hancock RE, Speert D. Antibiotic resistance in Pseudomonas aeruginosa: mechanisms and impact on treatment. Drug Resist Updat. 2000 Aug:3(4):247-255. 
9. Singh PK, Schaefer AL, Parsek MR, Moninger TO, Welsh MJ, Greenberg EP. Quorum sensing signals indicate that cystic fibrosis lungs are infected with bacterial biofilms. Nature. 2000 0ct;407(6805):762-764.

10. Stewart PS, Costerton JW. Antibiotic resistance of bacteria in biofilms. Lancet. 2001 July;358 (9276):135-138.

11. Wolcott R, Costerton JW, Raoult D, Cutler SJ. The polymicrobial nature of biofilm infection. Clin Microbiol Infect. 2013 Feb;19(2):107-112.

12. Dosler $\mathrm{S}$, Karaaslan E. Inhibition and destruction of Pseudomonas aeruginosa biofilm by antibiotics and antimicrobial peptides. Peptides. 2014 Dec;62:32-37.

13. Karatuna 0 , Yagci A. Analysis of quorum sensing-dependent virulence factor production and its relationship with antimicrobial susceptibility in Pseudomonas aeruginosa respiratory isolates. Clin Microbiol Infect. 2010 Dec;16(12):1770-1775.

14. Walkowiak J, Cichy W. Mukowiscydoza- nadal aktualny problem diagnostyczny i terapeutyczny. Przewodnik Lekarza. 2001;9:86-90.

15. Goździk J, Cofta S, Mukowiscydoza a infekcje. Przewodnik Lekarza. 2007;1:89-92.

16. Emerson J, Rosenfeld M, McNamara S, Ramsey B, Gibson RL. Pseudomonas aeruginosa and other predictors of mortality and morbidity in young children with cystic fibrosis. Pediatr Pulmonol. 2002 Aug;34(2):91-100.

17. Silva LVRF, Ferreira FA, Reis FJC, Britto MCA, Otavio $C$, Ribeiro JD. Pseudomonas aeruginosa infection in patients with cystic fibrosis: scientific evidence regarding clinical impact, diagnosis, and treatment. J Bras Pneumol. 2013 Jun-Aug;39(4):495-512.

18. Dlugaszewska J, Leszczynska M, Lenkowski M, Tatarska A, Pastusiak T, Szyfter W. The pathophysiological role of bacterial biofilms in chronic sinusitis. Eur Arch Otorhinolaryngol. 2016 Aug;273(8):1989-1994.

19. Stepanovic S, Vukovic D, Hola V, Bonawentura G, Djukić S, Ćwirković I, Ruzicka F. Quantification of biofilm in microtiter plates: overview of testing conditions and practical recommendations for assessment of biofilm production by staphylococci. APMIS 2007 Aug;115(8):891-899.

20. Moskowitz SM, Foster JM, Emerson J, Burns JL. Clinically Feasible Biofilm Susceptibility Assay for Isolates of Pseudomonas aeruginosa from Patients with Cystic Fibrosis. J Clin Microbiol. 2004 May;42(5):1915-1922.

21. Hall-Stoodley L, Costerton JW, Stoodley P. Bacterial biofilms: from the natural environment to infectious diseases. Nat Rev Microbiol. 2004 Feb;2:95-108.

22. Bjamsholt T. The role of bacterial biofilm in chronic infections. APMIS Suppl. 2013 May;136:1-51.

23. Costerton JW, Stewart PS, Greenberg EP. Bacterial biofilms: a common cause of persistent infections. Science. 1999 May;284(5418):1318-1322.

24. Potera C. Forging a link between biofilms and disease. Science. 1999 Mar;283(5409):1837-1839.

25. Mladina R, Skitarelić N, Musić S, Ristić M. A biofilm exists on healthy mucosa of the paranasal sinuses: a prospectively performed, blinded, scanning electron microscope study. Clin Otolaryngol. 2010 Apr;35(2):104-110.

26. Heydari S,Eftekhar F. Biofilm Formation and $\beta$-Lactamase Production in Burn Isolates of Pseudomonas aeruginosa. Jundishapur J Microbiol. 2015 Mar;8(3):e15514.
27. Bjarnsholt T, Givskov M. The role of quorum sensing in the pathogenicity of the cunning aggressor Pseudomonas aeruginosa. Anal Bioanal Chem. 2007 Jan;387(2):409-414.

28. Kirisits MJ, Jeffrey J. Margolis JJ, Purevdorj-Gage BL, Vaughan B, Chopp DL, Stoodley P, Parsek MR. Influence of the Hydrodynamic Environment on Quorum Sensing in Pseudomonas aeruginosa Biofilms. J Bacteriol. 2007 Nov;189(22): 8357-8360.

29. Breidenstein EB, de la Fuente-Núñez C, Hancock RE. Pseudomonas aeruginosa: all roads lead to resistance. Trends Microbiol. 2011 Aug;19(8):419-26.

30. Stover CK, Pham XQ, Erwin AL, Mizoguchi SD, Warrener $\mathrm{P}$, Hickey MJ et al. Complete genome sequence of Pseudomonas aeruginosa PA01, an opportunistic pathogen. Nature. 2000 Aug;406:959-64.

31. Sauer K, Camper AK, Ehrlich GD, Costerton JW, Davies DG. Pseudomonas aeruginosa displays multiple phenotypes during development as a biofilm. J Bacteriol. 2002 Feb;184:1140-54.

32. Rasamiravaka T, Quentin Labtani Q, Duez P, El Jaziri M. The Formation of Biofilms by Pseudomonas aeruginosa: A Review of the Natural and Synthetic Compounds Interfering with Control Mechanisms Biomed Res Int. 2015;Article ID 759348, 17 pages. 2015;2015:759348. doi: 10.1155/2015/759348. Epub. 2015 Mar 19.

33. Davies DG, Parsek MR, Pearson JP, Iglewski BH, Costerton JW, Greenberg EP. The involvement of cell-to-cell signals in the development of a bacterial biofilm. Science. 1998 Apr 10;280(5361):295-298.

34. Singh PK, Schaefer AL, Parsek MR, Moninger TO, Welsh MJ, Greenberg EP. Quorum-sensing signals indicate that cystic fibrosis lungs are infected with bacterial biofilms. Nature. 2000 Oct 12;407(6805):762-764.

35. Bjarnsholt $\mathrm{T}$, Jensen $\mathrm{PO}$, Fiandaca MJ, Pedersen $\mathrm{J}$, Hansen CR, Andersen CB, Pressler T, Givskov M, Høiby N. Pseudomonas aeruginosa Biofilms in the Respiratory Tract of Cystic Fibrosis Patients. Pediatr Pulmonol. 2009 Jun;44(6):547-558.

36. Ferreira AG, Leão RS, Carvalho-Assef AP, Folescu TW, Barth AL, Marques EA. Influence of biofilm formation in the susceptibility of Pseudomonas aeruginosa from Brazilian patients with cystic fibrosis. APMIS. 2010 Aug;118(8):606-612.

37. Hentzer M, Teitzel GM, Balzer GJ, Heydorn A, Molin S, Givskov M, Parsek MR. Alginate Overproduction Affects Pseudomonas aeruginosa Biofilm Structure and Function. J Bacteriol. 2001 Sep;183(18):5395-5401.

38. Taylor PK, Yeung AT, Hancock RE. Antibiotic resistance in Pseudomonas aeruginosa biofilms: towards the development of novel anti-biofilm therapies. J Biotechnol. 2014 Dec;10(191):121-130.

39. Aaron SD, Ferris W, Ramotar K, Vandemheen K, Chan F, Saginur $R$, Single and combination antibiotic susceptibilities of planktonic, adherent, and biofilm-grown Pseudomonas aeruginosa isolates cultured from sputa of adults with Cystic Fibrosis, J Clin Microbiol. 2002;(40)4172-4179.

40. Gupta P, Chhibber S, Harjai K. Subinhibitory concentration of ciprofloxacin targets quorum sensing system of Pseudomonas aeruginosa causing inhibition of biofilm 
formation \& reduction of virulence. Indian J Med Res. 2016 May;143(5):643-651.

41. Fricks-Lima J, Hendrickson CM, Allgaier M, Zhuo $H$, Wiener-Kronish JP, Lynch SV, Yang K. Differences in biofilm formation and antimicrobial resistance of Pseudomonas aeruginosa isolated from airways of mechanically ventilated patients and cystic fibrosis patients. Int J Antimicrob Agents. 2011 Apr;37(4):309-315.

42. Abdi-Ali A, Mohammadi-Mehr M, Agha Alaei Y. Bactericidal activity of various antibiotics against biofilm-producing Pseudomonas aeruginosa, International Journal of Antimicrobial Agents. 2006 Mar;27(3):196-200.

43. Furiga A, Lajoie B, El Hage S, Baziard G, Roques C. Impairment of Pseudomonas aeruginosa Biofilm Resistance to Antibiotics by Combining the Drugs with a New Quorum-Sensing Inhibitor. Antimicrob Agents Chemother. 2015 Dec 28;60(3):1676-1686.

44. Drenkard E. Antimicrobial resistance of Pseudomonas aeruginosa biofilms. Microbes Infect. 2003 Nov;5(13):12131219.
Acceptance for editing: 2016-12-10 Acceptance for publication: 2016-12-22
Correspondence address: Jolanta Długaszewska, PhD Poznan University of Medical Sciences Department of Genetics and Pharmaceutical Microbiology Święcickiego Street, 60-781 Poznan, Poland phone: +48618546720 fax: +48 618546720 